\title{
Supply Chain Management In The Ghanaian Building Construction Industry: A Lean Construction Perspective
}

\author{
Ali Boateng \\ Directorate Of Works And Physical Development, Kumasi Technical University, Kumasi - Ghana
}

\begin{abstract}
Supply Chain Management (SCM), for the past two decades, has been identified by manufacturing industries as a new way of doing business. Construction, just like the manufacturing and other services industries, is experiencing emerging trends that are aimed at giving ultimate satisfaction to the end user. Lean Construction is a way to design production systems in order to minimize waste of materials, time, and efforts that generate maximum possible amount of value. This research looked into how supply chain management can benefit the Ghanaian building construction industry through the application of lean concept. The purpose of this study is to assess the level of collaboration and coordination in planning of activities among construction industry players, and investigate into the sources of waste in construction. The study is considered as qualitative case study. Data is collected through questionnaires, in depth interviews and direct observation of on-going projects on KNUST campus. One sample $t$ test is used to analyze the data. The findings pointed out that the level of coordination and collaboration in planning among industry players were very appreciable though there still exist room for improvement.
\end{abstract}

(C) 2019 The Authors. Published by Budapest University of Technology and Economics \& Diamond Congress Ltd.

Peer-review under responsibility of the scientific committee of the Creative Construction Conference 2019.

Keywords: construction; lean; supply chain management; value; waste

\section{Introduction}

Supply Chain Management (SCM), for the past two decades, has been identified by manufacturing industries as a new way of doing business [1]. The ever changing manufacturing environment such as development of Information Technology (Internet), globalization and sophisticated customers who demand increasing product variety, lower cost, better quality and faster response has accounted for the implementation of this new approach. SCM as explained by Christopher [2] is concerned with the management of upstream and downstream relationships with suppliers and customers in order to deliver superior customer value at less cost to the supply chain as a whole. The primary focus of SCM, Christopher [2] continues, include seeking to achieve a linkage and coordination between the processes of other entities, reducing buffer of inventory that exist between organizations in a chain through information sharing, as well as ensuring cooperation and trust among all involved in the supply chain. 
Ali Boateng/ Proceedings of the Creative Construction Conference (2019) 060 https://doi.org/10.3311/CCC2019-060

Ayers [3], concludes that SCM has untapped potential for maintaining a competitive position or moving a company from an unfavourable to a more advantageous position. SCM therefore presents an especially important domain which is crucial to achieving a consistently successful performance.

Construction Supply Chain Management is an emerging area of practice which is inspired by but differs substantially from manufacturing SCM, which places emphasis on modeling volume production. Construction SCM on the other hand is concerned with the coordination of discrete quantities of materials delivered to specific construction projects [1]. The Construction industry generally is known to be a very vibrant and primary contributor to the economy of every nation in terms of employment generation and gross domestic product. This is evident in the employment opportunities it offers skilled and unskilled labour, from engineers and consultants to artisans and labourers [4]

Construction, just like the manufacturing and other services industries, is experiencing emerging trends that are aimed at giving ultimate satisfaction to the end user. As in the manufacturing context, construction companies are facing increasing competition and customers are requiring lower costs, higher quality, shorter execution durations and more reliable schedules [1]. The industry is characterized by the adoption of traditional methods of procurement and planning project executions with very little room for logistics and supply chain management. This has led to a situation where most projects are completed well over the contract duration whiles incurring avoidable costs, hence a reduction in turnover [1]. Inadequate management of logistics also has an adverse effect on quality, causes delays to projects, and adds to the health and safety risks on site. Additionally, construction supply chain is still full of waste and problems caused by myopic control [5].

One strategy for coordinating within and between firms with a focus on achieving efficiency, eliminating waste or overburden and creating value in products is the concept of lean management [6]. Ballard and Howell [7] further argue that construction project management is activity or contract centered, with transactional contracts or assignments defining and balancing the objectives of various participants thus making it ripe for the occurrence of costs and errors. Thus while project management views a project as the combination of activities, lean thinking views the entire project in the production system terms, that is, as if the project were one large operation.

Lean concept, which was coined in a book co - authoured by Jim Womack, Daniel Jones and Daniel Roos called "The Machine That Changed The World", evolved from the Toyota Production System in Japan and is a philosophy which considers the expenditure of resources for any goal other than the creation of value for the end customer to be wasteful, and thus a target for elimination [8].Holweg, [8] further defines "value" as any action or process that a customer would not be willing to pay for. This concept, which was originally designed to suit the manufacturing industry, has not allowed the construction industry to benefit fully as a result of the one of a kind type of production as against the mass production in manufacturing. Lean therefore employs continuous improvement efforts which focuses on eliminating waste or non - value adding steps along the supply chain.

Koskela et al, [9], defines Lean Construction as a way to design production systems in order to minimize waste of materials, time, and effort in order to generate the maximum possible amount of value. They further argue that, lean construction concerns itself with the holistic pursuit of concurrent and continuous improvements in all dimensions of the built and natural environment. This approach tries to manage and improve construction processes with minimum cost and maximum value by considering customer needs. The goals of lean construction, according to Ballard and Howell [7], redefine performance against three dimensions of perfection; (i) a uniquely custom product, (ii) delivered instantly with (iii) nothing in stores. This, they assert, is an ideal that maximizes value and minimizes waste. The formation of the International Group of Lean Construction that holds annual conferences has propagated the concept of Lean construction which according to Formoso and Moura, [10], the application of it has been widely successful in countries such as USA, Brazil, Chile, Ecuador, England, Finland, Denmark and other countries.

Whereas the application of supply chain management techniques has been known to save millions of dollars whiles improving on customer service in the manufacturing environment [11], its importance in the construction environment cannot be underestimated. Supply chain management promises an engineering basis to design, plan, and manage construction projects in a collaborative manner as against the current construction methods which takes a hierarchical, 
Ali Boateng/ Proceedings of the Creative Construction Conference (2019) 060

https://doi.org/10.3311/CCC2019-060

decomposition approach which seeks at best to optimize individual activities [1]. This ultimately tends to support the fragmentation that plagues the construction industry. On the other hand, according to Bertelsen, [12], a poorly designed supply chain regularly increases project costs by ten percent hence the need to employ best practices if the full benefits of supply chain management in construction are to be achieved.

Research on improving the quality, performance and delivery in the construction industry in Ghana through the adoption of lean concept largely centres assessing perceptions of lean construction philosophy, identifying level of knowledge, barriers to the adoption of lean construction and possible means to overcome these barriers as well as level of contribution of waste minimizing measures and the level of their practice of such measures [13], [14], [15], without identifying the sources of waste. The main motivation of this research is to provide an approach to improving the performance of the construction industry in Ghana through the concept of lean thinking. The objective of the study is to assess the level of collaboration and coordination in planning among construction industry players and also investigate into the sources and causes of waste in the construction industry. A theoretical framework for SCM and lean construction is developed in Section 2 of the study, whiles Section 3 deals with research methodology. Research results are analysed and discussed in Section 4. Finally, Section 5 concludes the study.

\section{Theoretical Framework}

\subsection{Supply Chain Management}

Stock And Boyer [6], while stating that there exist much confusion among researchers on the definition of SCM, do acknowledge commonalities like coordination, integration and cooperation among chain members. SCM, according to Christopher [3] is a network of connected and interdependent organisations mutually and co-operatively working together to control, manage and improve the flow of materials and information from suppliers to users. The primary concerns of SCM, Christopher [3] continues include (i) achieving linkages and coordination between processes, (ii) removing or eliminating buffers of inventory that exist between organisations in a chain through information sharing, (iii) ensuring co-operation and trust, (iv) managing relationships in order to achieve a more profitable outcome for all parties and (v) achieving competitive advantage.

The need for coordination between suppliers and distributors, in order to survive competition in the international market if further reinforced by Janvier - James [21]. Mentzer et al. [22] however simplify SCM activities to include integrated behavior, mutually sharing information, mutually sharing risks and rewards, cooperation, the same goal and the same focus on serving customers, integration of processes and partners to build and maintain long - term relationship.

\subsection{Lean Thinking}

Lean thinking was pioneered by the Toyota Production System (TPS) with a focus on waste elimination, continuous flow, and customer demand pull, which is otherwise referred in manufacturing as Just-in-Time production [16]. Lean thinking has three guiding principles according to Fitzsimmons and Fitzsimmons [16] and they are:

1. Satisfy the needs of the customer by performing only those activities that add value in the eyes of the customer.

2. Define the "value stream" by flowcharting the process to identify both value added and non-value added activities.

3. Eliminate waste. Waste in the value stream is any activity that the customer is not willing to pay for.

Ballard and Howell [7] on the other hand states the principles of lean thinking as (i) stopping the line, (ii) pulling product forward, (iii) one-piece flow, (iv) synchronise and align, and (v) transparency. 
Ali Boateng/ Proceedings of the Creative Construction Conference (2019) 060

https://doi.org/10.3311/CCC2019-060

\subsection{Lean Construction: Definition and Principles}

Koskela [17] explains that Womack and Jones in their book "The machine that changed the world" did not concisely summarized the principles of lean production. Hence in their newer book (1996), Womack and Jones endeavoured to improve the theoretical side of the discussion of lean production. Consequently, they summarized the principles underpinning lean thinking as:

- Precisely specify value by specific product

The central message of this principle is to rethink value from the perspective of the customer. The only thing that adds value in any type of process, is the physical or information transformation of the product, service or activity into something the customer wants.

- Identify the value stream for each product

Value stream is about modeling and designing of the production system, including product development, order fulfillment and the production proper, especially with the goal of weeding out avoidable wasteful activities.

- Make value flow without interruption

This principle, while addressing generally the reduction of lead times, refers basically to the method of onepiece flow, instead of a flow consisting of batches.

- Let the customer pull value from the producer

This principle means that the customer is pulling the product from the production system as needed rather than the production system pushing products, often unwanted, onto the customer.

- Pursue perfection

This is all about continuous minimization of waste and maximization of value, that is, continuous improvement.

\subsection{Lean "Wastes"}

Waste should be understood as any inefficiency that results in the use of equipment, materials, labour, or capital in larger quantities than those considered as necessary in the production of the activity. Waste therefore includes both the incidence of material losses and the execution of unnecessary work which generates additional cost but do not add value to the product [15]. Formoso et al. [10] also defined waste as any losses produced by activities that generate direct or indirect costs but do not add any value to the product from the point of view of the client. Ohno [18] defines waste into seven categories that are apparent in every manufacturing facility in the world. An eighth was added by Liker [19]:

1. Waste of overproduction

2. Waste of waiting

3. Waste of transport

4. Waste of over processing

5. Waste of inventory

6. Waste of motion

7. Waste of defects

8. Waste of unutilized people

- Waste of overproduction

This type of waste occurs when production is over what is immediately needed for use. That is, non - value adding use of available capacity leading to producing more and faster than the customer requires. Inventory stockpile, unbalanced material flow, extra resources and complex inventory management are some of characteristics of overproduction.

- Waste of waiting

This result from any idle time created whiles waiting such as idle time between operations or events. The waiting could be done by employees or customers, either of which is still a waste. Employees waiting for 
Ali Boateng/ Proceedings of the Creative Construction Conference (2019) 060

https://doi.org/10.3311/CCC2019-060

machines, machines waiting for employees, machines waiting from machines and unplanned equipment breakdown result in waiting related waste.

- Waste of transport

Any movement of materials or people around a plant that does not add value to the product or service is considered waste of transport. That is, movement of materials, finished goods, parts or information more than required resulting in wasted efforts and energy and adding to cost. Paperwork loop-back, large lot processing, multiple storage location and lack of work place organization give rise to transport waste.

- Waste of over-processing

This waste is about adding more value than the customer would pay for or any effort that adds no value to the product or service. In other words, processing more than required wherein a simple approach would have done. This generally results from lack of clear customer specification, endless refinement and ineffective policies and procedures.

- Waste of motion

Any movement of people or machines that does not add value to the product or service. Characteristically, excessive bending and reaching, looking for tools, machines or materials too far apart, confusing motion with work and lack of work place organization results in waste of motion.

- Waste of inventory

Storing parts, pieces, documentation ahead of requirements, that is, any supply in excess of customer requirements necessary to produce just in time is waste of inventory. Queuing, callers on hold, large storage areas, piles of request, use of large inventories and slow response to change result in this kind of waste.

- Waste of defect

Anything that does not meet customer needs leading to rework, scrap and inspection and repair of materials in inventory. This type of waste result in excessive human resource to rework, scrap, repair or inspect, missed shipment and deliveries and lower profit margins due to rework and scraps.

- Waste of unutilized people

When employees are not leveraged to their own potential, that is, using people to the best of their unique abilities, there is a waste of intellect. This usually results from lack of employee involvement, poor morale, status quo not challenged and lack of team activities and accountability.

\subsection{Lean Tools}

Numerous tools have been developed along with lean philosophy including, Kaizen, 5s, the Last Planner system, and the Value stream mapping. $5 \mathrm{~s}$ is a set of techniques providing a standard approach to housekeeping within Lean. Kaizen also deals with continuous improvement process where everyone is encouraged to come up with small improvement suggestions on a regular basis. Kanban on the other hand which means "signboard" or "billboard" and works on the basis that each process on a production line pulls just the number and type of components the process requires, at just the right time. It is a means to achieve Just-in-time [17].

\section{Methodology}

The research adopted a case study approach, with tools for data collection being face - to - face unstructured interviews, semi - structured questionnaires and direct observation. The cases studied involved 4 on-going building projects on the campus of KNUST. 10 construction professionals were interviewed, with 80 questionnaires administered. A total of 63 valid questionnaires were returned, representing a response rate of $78 \%$. Respondents were randomly sampled from all construction professionals employed on the building projects that were studied. Questionnaire was primarily in two parts. The first part was on collaboration and coordination in planning activities among industry players. In the second part, respondents were asked to rank, in order of importance on a 5 - point likert scale, 24 identified sources of waste on construction sites. Also, respondents were made to share their knowledge and understanding of waste, the possible consequences of waste, tools for waste identification and benefits to an organization on waste identification and elimination. The summary of building projects studied are in Table 1 below. 
Ali Boateng/ Proceedings of the Creative Construction Conference (2019) 060

https://doi.org/10.3311/CCC2019-060

Table 1: Characteristics of Case Projects

\begin{tabular}{lll}
\hline Project Name & Contract Sum (US\$) & Contractor \\
\hline Construction of 4 - Storey Examination Block & $5,500,000.00$ & Berock Ventures Limited \\
Construction Of 4 - Storey N - Block for the College of Engineering & $6,200,000.00$ & Berock Ventures Limited \\
Construction of VIP Ward for KNUST Hospital & $2,200,000.00$ & Stivo Company Limited \\
Construction of3 - Storey Computer Laboratory And Canteen Block for & $1,500,000.00$ & Asib Company Limited \\
KNUST JHS & & \\
\hline
\end{tabular}

Data collected was analysed using descriptive statistics and one - sample $\mathrm{t}-$ test at $95 \%$ confidence interval. Thus SPSS was used to calculate mean scores and standard deviations. Mean scores of greater than 3.00 were considered significant for the research [20]

\section{Results And Discussions}

\subsection{Coordination And Collaboration}

As seen from above, SCM largely thrives on coordination, co-operation and integration among all parties along the supply chain that have the ultimate goal of ensuring consumer satisfaction. Means scores as found in Table 2 below indicate that all other stakeholders have very cordial relationship among themselves. Clients rated the level of coordination and collaboration with other stakeholders highest, recording a mean of 4.67.

Table 2: Level of coordination and collaboration among industry players

\begin{tabular}{llccc}
\hline & $\mathrm{N}$ & Mean & Std. Deviation & Std. Error Mean \\
\hline Consultants & 63 & 4.48 & 0.602 & 0.131 \\
Subcontractors & 63 & 3.90 & 0.944 & 0.206 \\
Major Suppliers & 63 & 4.14 & 0.910 & 0.199 \\
Clients & 63 & 4.67 & 0.483 & 0.105 \\
\hline
\end{tabular}

\subsection{Communication And Information Sharing.}

Effective collaboration and coordination largely thrives on information sharing. Information sharing can also be as effective as the mode and effectiveness of communication. Respondents generally agreed that there existed a cordial relationship among all parties with respect to communication and information sharing. This is evident in all respondents having mean scores in excess of 3.00. Consultants indicated the greatest level of agreement, followed by Clients, subcontractors and major suppliers in that order, as indicated in Table 3 below. The modes include site meetings, letters, site instructions and phone calls. Electronic means such as emails were seldom used though communication between Sub Contractors and Main Contractors occasionally employed this mode.

Table 3: Communication and information sharing

\begin{tabular}{lcccc}
\hline & $\mathrm{N}$ & Mean & Std. Deviation & Std. Error Mean \\
\hline Consultants & 57 & 4.68 & 0.478 & 0.110 \\
Subcontractors & 60 & 4.30 & 0.571 & 0.128 \\
Major Suppliers & 60 & 4.25 & 0.550 & 0.123 \\
Clients & 63 & 4.43 & 0.746 & 0.163 \\
\hline
\end{tabular}

It came to light from the interview with the consultants that these meetings are held on monthly basis and may be reduced to bi-weekly when a particular project is nearing completion. It was also found out that aside monthly site meetings, technical meetings are scheduled to iron out critical and pressing issues that may arise in between monthly site meetings. Interviewees generally believed the regular nature of the meetings help to clearly define roles, address issues, set targets and source for ways of achieving them.

Site meetings and Technical Meetings provide an effective avenue for all parties to deliberate on issues bothering on the smooth execution of projects. It is at these meetings that wide range of issues that will promote the efficient site management and material deliveries are discussed. Other issues include the clarification of discrepancies in working 
Ali Boateng/ Proceedings of the Creative Construction Conference (2019) 060

https://doi.org/10.3311/CCC2019-060

drawings, waste generating activities and any other issues that militate against the smooth execution of projects are looked into and solutions found. Meetings also serve as a conflict resolution platform.

Since meetings bring together all these players under one umbrella at a time, coordination and collaboration is greatly enhanced. One set back that cropped up was that it was not an uncommon practice to find some members not present at these meetings. Members who absent themselves may sometimes delegate their subordinates to stand in for them but most of these subordinates may not be as resourceful and well informed as their superiors. As one interviewee puts it, it is not an uncommon occurrence to find the representative of the main or subcontractor not having information regarding the honouring or otherwise of payment certificates. He further continued that especially in cases where contractors are behind schedule and they are responsible for the delay, they tend to skip site meetings and prefer to be represented by their subordinates. On the part of Consultants, Structural, Services and Maintenance Engineers are not resident at the Office of Physical Development and due to other engagements by these persons, they may not be able to attend site meetings though their inputs may be required at the particular time.

Meetings aside, parties also communicated through the writing of letters and telephone calls. Contractors are encouraged to write letters to confirm oral instructions and channel concerns to Consultants as these letters form part of the contract. It was revealed by interviewees that the main mode of communication among subcontractors, main contractors and major suppliers is through telephone calls. Site Supervisors mostly said they often called Consultants over the phone to seek clarification or invite them to site to sort out urgent issues. They all agreed that the response rate was very appreciative though there still exist room for improvement. One Sub Contractor however stated that, there are times as a result of the bad nature of telecommunication service in the country, they have not been able to link up with people they may wish to contact. Consultants main concern was that request for information and clarification should be done well in advance to ensure that adequate and rich responses are given. This they say will prevent instances where responses are given in a rush which may prove not to be the best advice.

\subsection{Coordination In Planning}

The results prove that generally the various players took into account the concerns of others when planning their activities. This is because there exist healthy relationship among players. Respondents ranked the relationship that exists among them as very healthy. It was found out from the interview with subcontractors that they also see the relationship between themselves, main contractors, consultants and clients as very healthy. Consultants held the same view. The planning of activities by Main Contractors were influenced to a greater extent by Consultants, Sub Contractors and Major Suppliers and the reverse also holds true. This explains the higher levels of coordination among all parties. It is therefore not surprising to find activities such as defects, unnecessary work, poor storage of materials and poor quality of work are not usual occurrences on site and hence not a source of waste for the purpose of this study. Coordination in planning of activities by all parties ensures that work is done according to specification, doing the right thing at the right time and allocation of the right type and quantity of materials to the right type of activity. Table 3 summarizes the level of agreement to coordination in planning of activities.

Table 4: Coordination In Planning Of Activities

\begin{tabular}{lcccc}
\hline & N & Mean & Std. Deviation & Std. Error Mean \\
\hline Consultants & 63 & 4.57 & 0.746 & 0.163 \\
Sub Contractors & 60 & 3.65 & 1.137 & 0.254 \\
Major Suppliers & 60 & 3.30 & 1.380 & 0.309 \\
Clients & 60 & 4.20 & 1.005 & 0.225 \\
\hline
\end{tabular}

Strong coordination among parties on a project will be step in the right direction towards the successful completion of a project. This is because, individual companies with separate corporate interests have come together to execute a particular project. One Sub Contractor who installs Lift states that he can only move to site after the main contractor has finished with all concrete works related to the lift well. This he states further explains how reliant he is on the main contractor. He however agreed that the main contractor would also have to wait for him to finish with his works before making good any works disturbed. All interviewees agreed that they can hardly achieve the level of success required 
Ali Boateng/ Proceedings of the Creative Construction Conference (2019) 060

https://doi.org/10.3311/CCC2019-060

of them if they do not take into account the concerns and influences of other players. Team work, to them, is the watch word.

The picture is not all rosy as there is the need to still improve on the level of coordination in planning of activities among industry players as pointed out by one interviewee. Slow decision making and instructions by Consultants, shortages of materials and waste of materials proved to be significant sources of waste according to respondents and can directly be attributed to problems in the level of coordination in planning. Proper internal coordination in planning of activities should prevent other sources of waste like inefficient movement of workers and delays in arrival of workers. Externally, Consultants would also better appreciate the positive impact the timely issuance of instructions will have on the project.

\subsection{Wastes In Construction.}

For the purpose of this study, waste is understood to be any losses produced by activities that generate direct or indirect costs but do not add any value to the product from the point of view of the client. Respondents understood waste to mean one of the following: leftovers of materials on site, unwanted material, excess material not used after a construction activity, materials that are supposed to go into the works but do not find their way into the works, percentage of material which was not used as intended as a result of improper usage and/or supervision and any unwanted materials. In line with the set criteria, items $\mathrm{O}-\mathrm{X}$, with means scores of less than 3.00 were considered insignificant.

\begin{tabular}{|c|c|c|c|c|c|}
\hline Item & & $\mathrm{N}$ & Mean & Std. Deviation & $\begin{array}{c}\text { Std. Error } \\
\text { Mean }\end{array}$ \\
\hline A & Delays in arrival of workers, plant and materials & 63 & 3.7619 & 0.70034 & 0.15283 \\
\hline B & Slow decision making and instructions by Consultants & 63 & 3.6190 & 0.74001 & 0.16148 \\
\hline $\mathrm{C}$ & Waste of materials & 63 & 3.5238 & 0.74960 & 0.16358 \\
\hline $\mathrm{D}$ & Shortage of materials & 63 & 3.5238 & 0.87287 & 0.19048 \\
\hline $\mathrm{E}$ & Inefficient movement of workers & 63 & 3.3810 & 0.80475 & 0.17561 \\
\hline $\mathrm{F}$ & Poorly scheduled delivery of materials to site & 63 & 3.2857 & 0.84515 & 0.18443 \\
\hline G & Accidents & 63 & 3.2381 & 0.62488 & 0.13636 \\
\hline $\mathrm{H}$ & Excess materials in store & 63 & 3.1905 & 0.92839 & 0.20259 \\
\hline I & Waiting and idling & 63 & 3.1905 & 0.92839 & 0.20259 \\
\hline $\mathrm{J}$ & Double handling of materials & 63 & 3.1429 & 0.91026 & 0.19863 \\
\hline $\mathrm{K}$ & Use of materials over and above specifications & 63 & 3.1429 & 0.96362 & 0.21028 \\
\hline $\mathrm{L}$ & Deterioration of materials & 63 & 3.0952 & 0.76842 & 0.16768 \\
\hline M & Rework & 63 & 3.0476 & 0.80475 & 0.17561 \\
\hline $\mathrm{N}$ & Unnecessary or not enough information flow & 63 & 3.000 & 0.89443 & 0.19518 \\
\hline $\mathrm{O}$ & Waste of space on site & 63 & 2.9524 & 0.74001 & 0.16148 \\
\hline $\mathrm{P}$ & Defects & 63 & 2.9524 & 0.74001 & 0.16148 \\
\hline Q & Work not done & 63 & 2.9524 & 0.86465 & 0.18868 \\
\hline $\mathrm{R}$ & Over allocation of materials to an activity & 63 & 2.9524 & 0.97346 & 0.21243 \\
\hline $\mathrm{S}$ & Unnecessary work & 63 & 2.9048 & 0.88909 & 0.19401 \\
\hline $\mathrm{T}$ & Poor quality of materials & 63 & 2.8571 & 0.79282 & 0.17301 \\
\hline $\mathrm{U}$ & Poor storage of materials & 63 & 2.8095 & 0.74960 & 0.16358 \\
\hline $\mathrm{V}$ & Workers performing activities well below their capabilities & 63 & 2.8095 & 0.87287 & 0.19048 \\
\hline W & Abnormal use of equipment and tools & 63 & 2.7143 & 0.84515 & 0.18443 \\
\hline $\mathrm{X}$ & Inadequate storage spaces & 63 & 2.7143 & 0.84515 & 0.18443 \\
\hline
\end{tabular}

Another observation was that, respondents understood waste from the point of view of one or more of the categories of waste but certainly not all. Subcontractors generally preferred to consider excess materials in inventory as locking up their capital rather than waste. They also understood waste in relation to rework. Different from the above explanations, one respondent understood waste as activities carried out that do not add value and lead to loss of time, quality and cost. 
Ali Boateng/ Proceedings of the Creative Construction Conference (2019) 060

https://doi.org/10.3311/CCC2019-060

Respondents mostly did not define waste with respect to value adding as $57 \%$ said it was difficult for them to identify value adding activities. This give rise to situation where contractors are not able to identify all wastes and make them targets for reduction or elimination. Site observation confirmed this position because most Site Supervisors concerns at waste reduction were geared towards the efficient use of materials to prevent them from being wasted. Very little consideration was given to time related waste. From the findings, most activities which are time related such as delays in arrivals, slow decision making by consultants and inefficient movement of workers were usual occurrences on site. On the other hand, activities such as defects, over allocation of materials and work not done, which the respondents considered to generate waste, were not significant to this study, thus giving a clearer picture of the angle from which waste in construction is tackled from.

The above can be explained by the fact that $61.9 \%$ of respondents said they had no tools and techniques that helped them identify waste. In the absence of such tools, it only follows naturally that not all activities that generate waste would be captured. Overwhelming majority of $90.5 \%$ of respondents said they would like to introduce the concept of lean in their organization to help them identify and eliminate waste. Though most respondents were not familiar with lean concept, after a little explanation, they expressed willingness to adopt such a concept. One respondent, who has some knowledge on lean concept, though accepting to adopt this concept, was particularly concerned about the capital intensive nature of its implementation in the initial stages but agreed that it paid off in the long run. This study however, did not go into the monetary requirements and implications of implementing lean concept in construction.

Identifying value adding and non - value adding activities on site will greatly help in detecting activities that generate waste and subsequently target them for reduction and/or elimination.

\section{Conclusion}

Clients have become increasingly demanding and require products and services at lower costs, higher quality, shorter execution durations and more reliable schedules. In response to this, industries are reviewing their operations to meet the demands of the end user. In the light of the above, the author sort to study into how supply chain management can benefit the Ghanaian building construction industry through the application of lean concept. Specific areas that were target for study were to assess the level of collaboration and coordination in planning of activities among construction players and the sources of waste in construction.

Waste reduction is the best and usually the most economical of the different management alternatives. To implement an efficient waste reduction programme in the Ghanaian building construction industry, it is necessary to identify what is generating waste and its causes.

To achieve the above, the author through case study approach, gathered data through administering of questionnaires, in depth interviews and direct observation of construction sites on KNUST campus. Data collected were analyzed and the findings gave a clearer picture of the current practices in the construction industry, pointed out areas that needed commendation and those that needed improvement.

Waste is not only associated with waste of materials in the construction process, but also other activities that do not add value. Concepts such as waste and value are not well understood by construction personnel. They often do not realize that many activities they carry out do not add value to the work. These issues contribute to a reduction in the value of construction productivity and could reduce a company's performance and profitability. By identifying the incidence of waste during a project, construction personnel are able to easily identify the best solutions and ways to apply new technique for reducing the amount of waste, leading to increase project productivity. 
Ali Boateng/ Proceedings of the Creative Construction Conference (2019) 060

https://doi.org/10.3311/CCC2019-060

\section{References}

[1] O'Brien W. J., Formoso, C. T., Vrijhoef R. and London, K. A., Construction supply chain management handbook (2008).

[2] Christopher, M., Logistics and supply chain management. Prentice Hall (2016)

[3] Aryers, J. B., Supply chain strategies. Information Strategy: The Executive Journal. Spring (1999)

[4] Ofori, G., Developing the construction industry in ghana: The Case of a Central Agency, National University of Singapore, Singapore, available at www.ghanatrade.com/file/Developing the Construction Industry In Ghana BUILDING.pdf (2012)

[5] Vrijhoef R. and Koskela, L., Roles of supply chain management in construction. Proceedings of $7^{\text {th }}$ Annual Conference of International Group Of Lean Construction, Berkeley California, USA. (1998)

[5] Womack, J. D., and Jones, D. T., Lean thinking: banish waste and create wealth in your corporation. Revised and updated edition. New York Free Press (2003)

[6] Stock, J. R. and Boyers, S. L., Developing a concensus definition of supply chain management: a qualitative study. International Journal of Physical Distribution \& Logistics Management. Vol. 39, Iss 8 (2009)pp 690 - 711

[7] Ballard, G., and Howell, G., Shielding production: essential step in production control. Journal of Construction Engineering and Management, Vol. 124, No. 1 (1998) https://doi.org/10.1061/(ASCE)0733-9364(1998)124:1(11)

[8] Holweg, M., The genealogy of lean production. Journal of Operations Management 25(2), (2007) pp 420 - 437 https://doi.org/10.1016/j.jom.2006.04.001

[9] Koskela, L., Howell, G., Ballard, G., and Tommelein, I., The foundations of lean construction. Building in Value, R. Best, and G. de Valence, eds., Butterworth - Heinemann, Elsevieur, Oxford, UK (2002)

[10] Formoso, C. T., Isatto, E. L., and Hirota, E. H., Method for waste control in the building industry. Proceedings of $7^{\text {th }}$ Annual Conference of the International Group for Lean Construction (IGLC-7) (1999) at Berkeley, USA

[11] Arntzen, B. C., Brown, G. G., Harrison, T. P., and Trafton, L. L., Global supply chain management at digital equipment corporation. Informs Journal Of Applied Analytics, 25(1), (1995) pp 69 - 93 https://doi.org/10.1287/inte.25.1.69

[12] Bertelsen, S., Construction logistics I and II, materials management in the construction process. Copenhagen, Denmark: Boligministeriet, Bygge - og, Boligstyrelsen (1993).

[13] Ayarkwah, J., Agyekum, K., Adinyira, E. and Osei - Asibey, D., Perspectives for the implementation of lean construction in the Ghanaian construction industry, Journal of Construction Project Management, Vol. 2. No. 2 (2012) pp 345 - 359

[14] Ayarkwah, J., Agyekum, K., Adinyira, E. and Osei - Asibey, D., Barriers to successful implementation of lean construction in the Ghanaian building industry, Journal of Construction, Vol. 5. No. 21 (2012) pp 3 - 11

[15] Ayarkwah, J., Agyekum, K., and Adinyira, E., Barriers to sustainable implementation of lean construction in the Ghanaian building industry. Proceedings of $6^{\text {th }}$ Built Environment Conference, JHB, South Africa. July 31 - Aug. 2 (2011)

[16] Fitzsimmons J. A. and Fitzsimmons M. J., Service management. operations, strategy, information technology. $7^{\text {th }}$ Ed. McGraw Hill (2011)

[17] Koskela, L., Moving on - beyond lean thinking. Lean Construction Journal, 1(1) (2004)

[18] Ohno, T., Toyota production system: beyond large-scale production”. New York: Productivity Press (1988)

[19] Liker, J. K., The toyota way: 14 management principles from the world's greatest manufacturer. New York: London: McGraw-Hill (2004)

[20] Ofori G., Gang, G. and Briffet, C., Implementing environmental management systems in construction: lessons from quality systems. Building and Environment, Vol. 37 No. 12 (2002) pp: (1397-407) https://doi.org/10.1016/S0360-1323(01)00115-9

[21] Janvier - James, A. M., A new introduction to supply chains and supply chain management: Definitions and theories perspective. International Business Research, Vol. 5, No. 1 (2012) https://doi.org/10.5539/ibr.v5n1p194

[22] Mentzer, J.T., DeWitt, W., Keebler, J.S., Min, S., Nix, N.W., Smith, C.D. and Zacharia, Z. G., Defining supply chain management. Journal of Business Logistics, Vol. 22, No. 2 (2001) https://doi.org/10.1002/j.2158-1592.2001.tb00001.x 